\title{
Princípios de racionalidade ambiental na formação de professores para a educação
}

\section{profissional}

\author{
Principles of environmental rationality in teacher education for professional education \\ Principios de racionalidad ambiental en la formación docente para la educación profesional
}

Recebido: 26/02/2021 | Revisado: 06/03/2021 | Aceito: 13/03/2021 | Publicado: 20/03/2021

\author{
Márcia Madeira Malta \\ ORCID: https://orcid.org/0000-0003-2007-5969 \\ Instituto Federal de Educação, Ciência e Tecnologia do Rio Grande do Sul, Brasil \\ E-mail: marcia.madeira@ riogrande.ifrs.edu.br \\ Elisabeth Brandão Schmidt \\ ORCID: https://orcid.org/0000-0002-7961-7593 \\ Universidade Federal do Rio Grande, Brasil \\ E-mail: elisabethlattes@gmail.com
}

\begin{abstract}
Resumo
Este artigo objetiva refletir sobre as contribuições da Racionalidade Ambiental para a Educação Profissional. Busca contribuir com a formação de professores em instituições de Educação Profissional, em especial nos Institutos Federais de Educação, Ciência e Tecnologia. A pesquisa realizada foi teórica de abordagem hermenêutica com potencial interpretativo e compreensivo. Os elementos basilares de análise foram: Contextos históricos da Educação Profissional; pressupostos epistemológicos da gênese dos Institutos Federais; Organização do Instituto Federal do Rio Grande do Sul (IFRS). A partir da análise, emergiram princípios ontológicos de Educação Ambiental: Pertencimento ao campo do saber; Alteridade Pedagógica; Círculos Compreensivos e Cuidado Ambiental. Os resultados sinalizaram que a Racionalidade Ambiental está na gênese da concepção epistemológica dos Institutos Federais e que a formação de professores pode potencializar a Educação Ambiental na instituição. Conclui-se, ainda, que uma das principais alternativas para a Racionalidade Ambiental na Educação Profissional seja a formação de professores específica para a Educação Profissional, isto é, de forma contextualizada às suas especificidades.
\end{abstract}

Palavras-chave: Educação profissional; Formação de professores; Racionalidade ambiental.

\begin{abstract}
This paper aims to reflect on contributions of the Environmental Rationality to Professional Education. It attempts to contribute to teacher education in Professional Education institutions, particularly the Federal Institutes of Education, Science and Technology. The research is theoretical, with a hermeneutical approach, and interpretative and comprehensive potential. The basic elements of analysis are the following: Historical contexts of Professional Education; Epistemological assumptions about the genesis of the Federal Institutes; Organization of the Federal Institute of Rio Grande do Sul. The following ontological principles of Environmental Education have emerged from the analysis: Belonging to the field of knowledge; Pedagogical otherness; Comprehensive circles; Environmental care. The results have evidenced that the Environmental Rationality is in the genesis of the epistemological conception of the Federal Institutes, and that teacher education may potentialize Environmental Education in the institution. It has also been concluded that one of the main alternatives to Environmental Rationality in Professional Education is specific teacher education for Professional Education, i.e. contextualized according to its specificities.
\end{abstract}

Keywords: Professional education; Teacher education; Environmental rationality.

\section{Resumen}

Este artículo tiene como objetivo reflexionar sobre los aportes de la Racionalidad Ambiental a la Educación Profesional. Busca contribuir a la formación de docentes en instituciones de Educación Profesional, especialmente en los Institutos Federales de Educación, Ciencia y Tecnología. La investigación realizada fue teórica con un enfoque hermenéutico con potencial interpretativo y comprensivo. Los elementos básicos de análisis fueron: contextos históricos de la educación profesional; Supuestos epistemológicos de la génesis de los Institutos Federales; Organización del Instituto Federal do Rio Grande do Sul. Del análisis surgieron los principios ontológicos de la Educación Ambiental, estos son: Pertenecientes al campo del conocimiento; Alteridad Pedagógica; Comprensión de los círculos y el cuidado del medio ambiente. Los resultados señalaron que la Racionalidad Ambiental está en el origen de la concepción epistemológica de los Institutos Federales y que la formación docente puede potenciar la Educación Ambiental en la institución. También se concluye que una de las principales alternativas de Racionalidad Ambiental en la Educación Profesional es la formación de docentes específicos para la Educación Profesional, es decir, de manera contextualizada a sus especificidades. 
Palabras clave: Educación profesional; Formación de profesores; Racionalidad ambiental.

\section{Introdução}

A Educação Profissional passou por diferentes concepções e, nesse percurso, desenvolveu-se em cenários cuja racionalidade predominante era a instrumental, racionalidade esta que contribuiu para patologias sociais oriundas de uma crise civilizatória.

Podemos perceber que, nesse processo de transformação social, uma crise ontológica se consolidouem uma ordem capitalista, consumista e individualista. Nesse contexto, aspectos como a apropriação da natureza em prol de uma ciência positivista, o pensamento colonizador, a fragmentação do conhecimento e os meios de produção capitalista que causaram e ainda causam uma crise civilizatória influenciaram não só o campo epistemológico científico, mas também as relações existenciais da humanidade.

Com base nesses pressupostos, este artigo objetiva propor reflexões sobre as contribuições da Racionalidade Ambiental para a Educação Profissional. Compreendemos que a Racionalidade Ambiental pode constituir-se no "vir-a-ser" no processo educativo dos Institutos Federais de Educação, Ciência e Tecnologia. Defendemos a ideia de que, para construção, fortalecimento e vivência da Racionalidade Ambiental nos Institutos Federais, é importante que a formação de professores tenha por base princípios de Racionalidade Ambiental.

\section{Metodologia}

A pesquisa realizada é de cunho qualitativo; "os métodos qualitativos são aqueles nos quais é importante a interpretação por parte do pesquisador com suas opiniões sobre o fenômeno em estudo" (Pereira et al., 2018, p. 67). A pesquisa qualitativa investiga os fenômenos a partir de informações, possibilitando a interpretação e compreensão dos aspectos observados e analisados.

As pesquisas qualitativas podem apresentar diferentes abordagens, sendo uma delas a abordagem hermenêutica, com viés interpretativo e compreensivo. A hermenêutica apresenta-se como um potencial epistemológico e metodológico para as pesquisas em educação por ser reflexiva e dialógica e ter como foco a compreensão de fenômenos.

[...] a perspectiva hermenêutica nos permite compreender e considerar integradamente as questões ideológicas, políticas e científicas, possibilitando-nos saber mais plenamente sua interdependência e influências mútuas desse complexo processo de construção do conhecimento científico em educação. (Ghedin \& Franco, 2008, p. 129).

Diferentemente de pesquisas tradicionais, a abordagem hermenêutica propõe a horizontalidade do diálogo e a produção de sentidos, isto é, a interpretação de textos e contextos, lidos ou falados: esse processo já é o caminho metodológico, "[...] que assume a postura hermenêutica fenomenológica como possibilidade de diálogo junto às produções bibliográficas que utilizamos para a construção do estudo". (Claro, 2018, p. 20). Seu caráter compreensivo e interpretativo oportuniza a análise de diferentes contextos sociais, que abrangem o político, o econômico, o estético e o cultural.

A utilização da hermenêutica para a pesquisa qualitativa abre um grande caminho para além dos textos, entrevistas e discursos. A hermenêutica relaciona a ciência à arte e à história como possibilidades para o desenvolvimento de uma interpretação. Isso aponta para que outras atividades ou formas de expressão do homem possam ser contempladas pelo estudo hermenêutico e assim produzir conhecimento a partir de fontes não necessariamente textuais. (Saraçol, Dolci \& Pereira, 2016, p. 72). 
Somos produtos desses cenários comunicativos e absorvidos, de culturas, tradições e racionalidades que se constituem. Pode-se dizer que "[...] a hermenêutica parte de uma proposta que não só reinventa as bases das ciências humanas, como busca retomar uma dimensão ontológica no campo da produção dos conhecimentos”. (Claro, 2018, p. 40). Para responder o questionamento da pesquisa a partir do horizonte hermenêutico, são trazidos elementos basilares para interpretação e compreensão:

1 - Contextos históricos da Educação Profissional;

2 - Pressupostos epistemológicos da gênese dos Institutos Federais;

3 - Organização do IFRS, em especial, do Campus Rio Grande.

Boff, Pereira e Levinas, dentre outros pesquisadores, foram teóricos selecionados para o embasamento dos argumentos construídos ao longo da pesquisa.

\section{Resultados e discussão}

A pretensão desta pesquisa foi a de investigar questões inerentes à Racionalidade Ambiental para a Educação Profissional nos Institutos Federais de Educação (IFs), Ciência e Tecnologia, com o intuito de obter subsídios para pensar e fortalecer a Educação Ambiental na Instituição. Ao longo da pesquisa, de cunho hermenêutico, compreendemos que o paradigma de Educação Profissional proposto pelos Institutos Federais apresenta pressupostos epistemológicos de Racionalidade Ambiental que contribuíram para a transformação do paradigma de Educação Profissional decorrente da criação dos IFs.

Faz-se necessário que novas pesquisas sejam realizadas para se avaliar a inserção da Educação Ambiental nas demais áreas do conhecimento e nos demais cursos de graduação, principalmente nas universidades públicas, pois, como anunciada em diversos instrumentos legais, a Educação Ambiental, para provocar as mudanças necessárias, necessita ser desenvolvida como uma prática educativa integrada e interdisciplinar, contínua e permanente em todas as fases, etapas, níveis e modalidades de ensino. (Pereira et al., 2020, p. 27).

Entendemos que a formação de professores pode potencializar a Racionalidade Ambiental;portanto, nesse sentido, apresentamos quatro princípios como base epistemológica para a formação docente da Educação Profissional. São eles: pertencimento ao campo do saber; alteridade pedagógica; círculos compreensivos; e cuidado ambiental.

\section{Pertencimento ao Campo do Saber}

A Educação Profissionalapresenta diversas características, sendo importante que o futuro docente as conheça e compreenda, sabendo pensar sobre a docência de forma contextualizada.

Para que a formação de professores contribua com a construção da Racionalidade Ambiental entre os futuros docentes da Educação Profissional, faz-se necessário, inicialmente, refletir sobre o sentir-se parte, sobre o sentimento e percepção de pertencimento ${ }^{1}$ a esse lugar ${ }^{2}$ da Educação Profissional. Isto significa construir a percepção de pertencimento ao campo de atuação profissional. Perceber-se pertencente, além de condição para o processo identitário docente, pode ser o ponto

\footnotetext{
${ }^{1}$ Cousin (2010, p. 95) afirma que: "a capacidade de sintonia com o outro exige compartilhar um pertencimento. Considero importante que a sociedade compartilhe o mundo e construa o sentimento de pertencer a um modo de vida e a um contexto que está sendo constantemente produzido e transformado e reflita sobre o seu papel enquanto sujeito envolvido nesse processo. O pertencimento possibilita compreender como os processos das relações sociais estão presentes em cada vivência e como o local e o global se traduzem em experiências individuais e coletivas.

${ }^{2}$ Lugar, aqui, refere-se tanto ao campo do saber quanto à instituição.
} 
impulsionador para outros modos de ser e estar na Educação Profissional, pelas reflexões e percepções realizadas. Sobre o processo de percepção, Merleau-Ponty $(1999$, p. 6) escreve que:

A percepção não é uma ciência do mundo, não é nem mesmo um ato, uma tomada de posição deliberada; ela é o fundo sobre o qual todos os atos se destacam e ela é pressuposta por eles. O mundo não é um objeto do qual possuo comigo a lei de constituição; ele é o meio natural e o campo de todos os meus pensamentos e de todas as minhas percepções explícitas.

Tal percepção está relacionada ao conhecimento e à compreensão de contextos, sejam eles de processos históricos e/ou institucionais, sejam de fenômenos. Merleau-Ponty (1999, p. 14) afirma que: “[...] buscar a essência da percepção é declarar que a percepção é não presumida verdadeira, mas definida por nós como acesso à verdade". Perceber as características e especificidades da Educação Profissional, bem como de suas instituições, implica refletir, ampliar a compreensão da rede de interações nela existentes. $\mathrm{O}$ autor ainda destaca que:

O mundo é não aquilo que eu penso, mas aquilo que eu vivo; eu estou aberto ao mundo, comunico-me indubitavelmente com ele, mas não o possuo, ele é inesgotável. "Há um mundo", ou, antes, "há o mundo"; dessa tese constante de minha vida não posso nunca inteiramente dar razão. (Merleau-Ponty, 1999, p. 14).

De acordo com o mencionado anteriormente, construir o sentimento de pertença sobre e na prática docente para a Educação Profissional requer sentir-se parte deste campo de atuação. Mas como sentir-se parte de um campo de atuação que muitas vezes não se fez presente em sua trajetória de vida? Há professores que não conviveram com a Educação Profissional em seu processo discente, ou até mesmo aqueles que desenvolveram seu processo formativo em licenciaturas não direcionadas ao campo da Educação Profissional. Assim, faz-se necessário que a compreensão inicial seja de que essa área do conhecimento tem uma trajetória histórica perpassada por diferentes territórios, tendências e perspectivas, portanto, importante de ser conhecida e compreendida.

A Educação Profissional constituiu-se e ainda se constitui em diferentes lugares. Porém, ao se resgatarem fatos, nem sempre os lugares são problematizados, o que muitas vezes torna a percepção e a compreensão sobre eles limitadas à percepção de lugar, isto é, reduzida ao espaço. Sobre lugares, Grün (2008, p. 3) afirma que:

Devido à ciência moderna, nós perdemos a noção de lugar, e estes [lugares] perderam sua autenticidade. Para um cientista moderno, todos os lugares são iguais, o que equivale a dizer, são espaços homogêneos, onde nos guiamos mais por coordenadas e sistemas de referência do que por descrições particulares com valores estéticos, religiosos e éticos.

Para construir a noção de pertencimento, consideramos importante e necessário compreender o lugar de forma ampla, e não apenas como espaço, abrangendo aspectos que estão além do físico, isto é, o social, o cultural, o econômico e o estético. Grün $(2008$, p. 3) questiona o fato de que "[...] as narrativas pelas quais damos sentido às nossas vidas dificilmente estão enlaçadas a lugares. Quase não há referência a lugares". Nesse sentido, a compreensão sobre a Instituição de Ensino de Educação Profissional, em especial sobre os Institutos Federais, como lugar de pertencimento possibilita a vivência da valorização do lugar e da Racionalidade Ambiental, diferentemente de uma percepção restritamente instrumental. Quando convivemos em um lugar e, um tempo depois, retornamos à convivência, percebemos e sentimos de forma diferente, de acordo com as especificidades daquele momento, daquele tempo. Assim, o lugar se dá pela estrutura e pelo acontecimento (Marandola, Holzer \& Oliveira, 2014). O significante está ligado ao físico, isto é, está restrito ao espaço; já o significado abrange o social, ou seja, amplia a percepção de lugar. 
Aliada à compreensão do campo da Educação Profissional, bem como das instituições que o constituíram, para a abordagem da percepção de pertencimento, consideramos importante refletir também sobre o "si". Cabe pensar nos lugares que nos constituíram, por meio da "semiótica do lugar", que compreende: meio social, meio físico, falar, habitar, conceitualização e figuração. Para Relph (2014, p. 22), lugar é diferente de lugares. Segundo o autor, “um lugar 'reúne' ou aglutina qualidades, experiências e significados em nossa experiência imediata, e o nome se refere a lugar de uma reunião específica e única". Essa perspectiva fenomenológica nos faz repensar nossa trajetória e perceber o quanto situações vividas, lugares vivenciados e pessoas com quem interagimos influenciam nossa constituição."A prioridade do espaço sobre o lugar é axiomática. A questão que se coloca para a Educação Ambiental é como fazer uma reapropriação social dos lugares para podermos ter uma noção de lugar e, assim, engendrar práticas mais orientadas ecologicamente e mais situadas”. (Grün, 2008, p. 4).

Portanto, percebemos o quanto a percepção de pertencimento ao lugar e o repensar os processos constitutivos são fundamentais para a construção de uma Racionalidade Ambiental. Constituímo-nos atribuindo sentidos e significados por meio da linguagem, e "[...] o sentido do lugar implica o sentido da vida e, por sua vez, o sentido do tempo" (Marandola Júnior et al., 2014, p. 3), onde estão em constante interação as realidades subjetiva e objetiva. O sentido atribui-se pelo cuidado, pelo juízo, pela direção, pela sensibilidade; conforme Grün (2008, p.4), “[...] nós estamos sempre em lugares, não vivemos no espaço, mas a percepção predominante é ainda a do espaço desnudo de qualidades".

A ideologia individualista da cultura industrial capitalista moderna construiu uma representação da pessoa humana como um ser mecânico, desenraizado e desligado de seu contexto, que desconhece as relações que o tornam humano e ignora tudo que não esteja diretamente e imediatamente vinculado ao seu próprio interesse e bem-estar. (Sá, 2005).

Construir a percepção de si e de pertencimento reforça nosso sentimento de coletividade nos processos vivenciados, muitas vezes ofuscado por ideologias individualistas e instrumentais, as quais precisam ser desconstruídas. O sentimento de coletividade nas relações vivenciadas, nas interações construídas e nos diálogos estabelecidos é primordial à construção de uma Racionalidade Ambiental.

A compreensão de pertencimento, tanto em relação ao campo do saber, quanto no que se refere à instituição de Educação Profissional, vista como lugares que se revelam e se transformam, carregados de peculiaridades, mostra a importância da individualidade para o processo de coletividade e reforça vínculos nas relações destes ambientes. Cada um de nós tem sua importância no processo educativo. A formação de professores para a Educação Profissional tem o desafio de adentrarnas especificidades deste campo do saber, com foco no desenvolvimento do sentido de pertença para que os docentes deixem de simplesmente atuar "na" Educação Profissional, passando a ser docentes "da" Educação Profissional. Com isso, ampliam-se as possibilidades do viver bem, do cuidado, da empatia, do respeito e de tantos saberes ambientais que viabilizam a Racionalidade Ambiental, manifestando a importância da alteridade pedagógica como princípio para a formação docente.

\section{Alteridade Pedagógica}

Na Educação Profissional, como em outras áreas da Educação, emergem práticas docentes de racionalidade instrumental; muitas vezes configuradas como práticas pedagógicas tradicionais, revelam uma espécie de "arrogância epistemológica", tratando pessoas de diferentes áreas de forma pejorativa e até hostil, como se existisse saber mais e saber menos, ou até mesmo uma hierarquização de saberes. Esse processo pode ocorrer por diferentes razões, seja pela falta de formação pedagógica inicial ou continuada dos docentes, seja pela cultura escolar, seja pela formação pedagógica fragilizada epistemologicamente. Cabe ressaltar que a alteridade, enquanto princípio educativo durante a formação docente, pode modificar formas de pensar e de agir e contrapor esse processo historicamente construído.

A primeira compreensão necessária é a da “[...] categoria 'alteridade', dentro da categoria 'autrui', isto é, o outro homem que está no mundo além do meu mundo". (Guareschi, 1998, p. 157). Somos possibilidades em constante transformação 
e diversidade. Somos todos diferentes, sujeitos biopsicoambiespirituais, conforme Pereira (2016). Somos constituídos em diferentes contextos econômicos, políticos, culturais e religiosos. Portanto, além de diferentes, somos metamorfoses - fomos, somos e seremos sempre "para além de". Somos seres de possibilidades, e não cabe aos docentes restringir, limitar ou mesmo destruir tais possibilidades.

Aqui, torna-se importante o que Levinas (1980) chama de hospitalidade, um lugar para acolher o outro. Sobre acolhida como ensinamento, Derrida (2008, p. 36) ressalta que:

É então receber [sublinhado por Lévinas] do Outro para além da capacidade do eu; o que significa exatamente: ter a ideia do infinito. Porém, isto significa também ser ensinado. A relação com o Outro ou o Discurso é uma relação nãoalérgica, uma relação ética, porém este discurso acolhido [eu sublinho ainda] é um ensinamento. Porém, o ensinamento não retorna à maiêutica. Ele vem do exterior e me traz mais do que eu contenho.

Assim, podemos perceber a alteridade como possibilidade para uma Educação Profissional mais humana e compromissada com relações interpessoais sob a perspectiva do cuidado, da ética da Racionalidade Ambiental. Se essa acolhida e modos de ser e estar no processo de Educação Profissional forem trabalhados desde a formação inicial e continuada dos docentes, possivelmente, os estudantes que os tiverem como referência assumirão uma conduta profissional com valores mais transcendentes e emancipatórios. Quando a alteridade pedagógica é considerada, o docente, além de colocar-seno lugar do discente, consegue visualizá-lo como um ser de possibilidades.

Faz-se necessário, na perspectiva da alteridade, saber ouvir e compreender, tendo em vista que compreender o outro é, de certa forma, compreender a si mesmo. Trata-se de cuidar, de construir uma racionalidade que se preocupa com as outridades, contribuindo para uma Racionalidade Ambiental.

Pensar na perspectiva da alteridade como princípio para a Educação Profissional a partir da Racionalidade Ambiental é, antes de mais nada, pensar no outro como ser de possibilidades, não restrito a hierarquias de saberes, fragmentações e dualismos que separem: teoria e prática; ciências humanas e exatas; perspectiva individualizada e coletiva. É preciso promover uma formação docente que incentive o princípio da Alteridade Pedagógica como contribuição à Racionalidade Ambiental, segundo Lévinas (1980), baseada em acolhimento ao outro, hospitalidade, transcendência e percepção do outro como além de, ou seja, percepção das outridades no que está além do aparente, compreendendo-as como sujeitos em construção permanente.

\section{Círculo Compreensivo}

A Racionalidade Ambiental implica saberes e fazeres que proporcionem a qualidade de vida por meio de formas de ser e estar que respeitem as outridades. Consideramos que um dos princípios a serem construídos na formação de professores para que esse processo ocorra seja o Círculo Compreensivo, o qual consiste na possibilidade de mobilizar ao debate e à perspectiva pedagógica da horizontalidade. Conforme esse princípio, todos e todas as participantes têm a oportunidade de fala e de escuta, não havendo postura hierárquica, portanto, vertical, de poder autoritário. Há, sim, diferentes papéis, seja de quem mobiliza e medeia, seja de quem se expressa e reflete. Os círculos compreensivos articulam-se aos princípios do pertencimento e da alteridade, abordados anteriormente, uma vez que suscitam a importância da perspectiva individual na coletiva e viceversa, na inter-relação entre o eu e o nós. Nessa relação dialógica³ ${ }^{3}$ crítica e reflexiva, constrói-se a compreensão recíproca sobre as outridades. Além de que:

\footnotetext{
3“'A relação dialógica, porém, não anula, como, às vezes, se pensa, a possibilidade do ato de ensinar. Pelo contrário, ela funda este ato, que se contempla e se sela no outro, o de aprender, e ambos só se tornam verdadeiramente possíveis quando o pensamento crítico, inquieto, do educador ou da educadora não freia a capacidade de criticamente, também, pensar ou começar a pensar do educando". (Freire, 2016, p. $118)$.
} 
Essa configuração em roda facilita a comunicação. Os sujeitos conseguem se olhar, e, com isso, as interações acontecem com mais facilidade. Ocorrem trocas de olhares, trocas de argumentos, trocas de críticas, trocas de experiências. Quando se está em roda, as trocas acabam sendo inevitáveis; conseguimos por meio dela conhecer um pouco do outro, observando seu comportamento, suas reações e manifestações. (Albuquerque \& Galiazzi, 2011, p. 388).

O Círculo Compreensivo abrange características que vão ao encontro dos círculos de cultura ${ }^{4}$ criados e trabalhados por Paulo Freire (2005), das rodas de conversas propostas por Cecília Warschauer (2001) e das rodas de formação ${ }^{5}$ de Lima (2011). Além da importância do processo de construção participativa, o Círculo Compreensivo, na perspectiva do diálogo, da conversa, é uma oportunidade coletiva de compreensão das outridades, de partilhas, de escutas e de construção de outras possibilidades de ser e estar no mundo, com base no cuidado e na qualidade de vida. Os círculos compreensivos buscam, na formação de professores, a construção de uma Racionalidade Ambiental para a Educação Profissional. A respeito do processo de conversar, Warschauer (2001, p. 179) afirma: “conversar não é só desenvolver a capacidade de argumentação lógica, como propor a presença física do outro, implica as capacidades relacionais, as emoções, o respeito, saber ouvir e falar, aguardar a vez, inserir-se na malha da conversa, enfrentar as diferenças, o esforço de colocar-se no ponto de vista do outro etc. [...]”.

A questão que se coloca é a importância de que os discentes dos cursos de licenciaturas e demais cursos de formação de professores que se preparam para atuar na docência para a Educação Profissional ampliem a capacidade de interpretação e compreensão das falas, dos silêncios, dos contextos, das outridades.

No que se refere à importância da interpretação e da compreensão, Heidegger (2015, p. 215) esclarece:

Toda interpretação funda-se no compreender. O sentido é o que se articula como tal na interpretação e que, no compreender, já se prelineou [sic] como possibilidade de articulação. Como o enunciado (o "juízo") se funda no compreender, representando uma forma derivada de exercício de interpretação, ela também "tem" um sentido. O sentido, porém, não pode ser definido como algo que ocorre em um juízo ao lado e ao longo do ato de julgar. [...]. (grifo do autor).

Nos círculos compreensivos, todas e todos os participantes sentem-separte do processo de discussão. Os sentidos atribuídos são desconstruídos a partir de diferentes interpretações e compreensões, e reconstruídos a partir de novos significados, por meio das interações. Vale salientar que a perspectiva do círculo vai além do "estar em roda" do ponto de vista da disposição física. O círculo, assim como a roda,é uma metáfora que representa as conexões e inter-relações que se estabelecem no processo de construção do conhecimento pelos diferentes estímulos proporcionados pelo círculo. O círculo não fragmenta, não exclui, não dualiza.

Esse princípio está intimamente ligado à perspectiva de uma Racionalidade Ambiental para a docência "na" e "da" Educação Profissional, uma vez que abrange a ampliação de saberes e de modos de ver e ler o mundo, outras possibilidades de ser e estar com compromisso ético e socioambiental no campo técnico e tecnológico. Essa interação favorece um pensar sobre novas técnicas ou tecnologias que se fundamentam em uma sustentabilidade substantiva. Para Boff (2013), a sustentabilidade deveria ser praticada no ramo das indústrias e demais empresas, não apenas para cumprir a lei, restringindo-se, segundo ele, a uma sustentabilidade adjetiva. Para o autor, tal perspectiva somente qualifica, mas não transforma.

Portanto, o Círculo Compreensivo como processo de interpretação, de ampliação das formas de ver e agir, pode engendrar processos educativos que contribuam para outros saberes, em especial a Racionalidade Ambiental para a Educação

\footnotetext{
4“'Constitui-se como um espaço dinâmico de aprendizagem e troca de conhecimento. Local onde se reuniam os sujeitos do processo de educação de adultos para debaterem problemas de interesse do próprio grupo. Representa uma situação-problema, representativa de situações reais, que busca levar à reflexão acerca da própria realidade, para, na sequência, decodificá-la, conhecê-la." (Vasconcelos \& Brito, 2011, p. 53).

${ }^{5}$ Para Warschauer (2001), a roda representa o símbolo para viabilizar o diálogo, a troca de experiências, a construção de conhecimentos com sentido para seus sujeitos.
} 
Profissional,fortalecendo posturas éticas e ambientalmente compromissadas com a qualidade devida das outridades. O Círculo Compreensivo, como princípio para a formação de professores da Educação Profissional, tem importância para:

[...] reinventar um novo modo de estar no mundo com os outros, com a natureza, com a Terra e com a última realidade. Aprender a ser mais com menos e a satisfazer nossas necessidades com sentido de solidariedade para com os milhões que passam fome e com o futuro de nossos filhos e netos. Ou mudamos ou vamos ao encontro de previsíveis tragédias ecológicas e humanitárias. (Boff, 2013, p. 11).

No diálogo sobre saberes ambientais necessários é que o futuro docente estará mais preparado para atuar com compromisso ético em suas diferentes áreas técnicas ou tecnológicas. A tríade ensino, pesquisa e extensão será pautada por um desenvolvimento preocupado com todas as formas de vida, isto é, um desenvolvimento tecnológico na perspectiva do cuidado ambiental que não sobreponha o lucro em detrimento da vida.

O Círculo Compreensivo é cuidado com o outro, é a chamada atenta do docente para com o discente sobre as necessárias intervenções, sobre quebra de paradigmas, sobre a desconstrução conceitual, sobre romper com as dualidades e perceber, de forma integrada, saberes e práticas, conceitos e técnicas, campo de trabalho e pessoas.

\section{Cuidado Ambiental}

A formação de professores oportuniza momentos de importantes reflexões para a constituição do ser docente. O diálogo crítico e coletivo abre diferentes olhares e leituras sobre as áreas do conhecimento debatidas e o contexto escolar, dentre outros aspectos. Principalmente, propicia a construção de conhecimentos acerca do fazer docente nas dimensões humana, técnica, político-social e ou estética. Nesse sentido, o cuidado ambiental torna-se necessário em todas essas complexas dimensões. Quais razões o tornam tão importante? Para discorrer sobre elas, é preciso definir o que é cuidado ambiental.

O cuidado ambiental, aqui proposto, transcende questões relacionadas à natureza ou à sustentabilidade. Ele pode ser entendido como um modo de ser cuidadoso, baseado no viver afetuoso, no sentido de afetar o ambiente no seu sentido amplo. Trata-se de uma busca ontológica que parte de si, da responsabilidade e do respeito às outridades nas suas mais diferentes formas de relacionamento. Para Boff (1999, p.11), "[...] o mundo virtual criou um novo habitat para o ser humano, caracterizado pelo encapsulamento sobre si mesmo e pela falta do toque, do tato e do contato humano". Segundo o autor, o cuidado é, na verdade, "o suporte real da criatividade, da liberdade e da inteligência. [...] no cuidado identificamos os princípios, os valores e as atitudes que fazem da vida um bem-viver e das ações um reto agir”. Por isso, é preciso considerar a atenção com as escutas, os silêncios, os gestos, as ações, as reações, entre tantos outros modos de ser e estar na e com a vida. Boff (1999, p. 14) complementa:

O cuidado serve de crítica à nossa civilização agonizante e também de princípio inspirador de um novo paradigma de convivialidade. [...] Sonhamos com um mundo ainda por vir [...] Sonhamos com uma sociedade mundializada, na grande casa comum, a Terra, onde os valores estruturantes se constituirão ao redor do cuidado com as pessoas, sobretudo com os diferentes culturalmente, com os penalizados pela natureza ou pela história, cuidado com os espoliados e excluídos, as crianças, os velhos, os moribundos, cuidado com as plantas, os animais, as paisagens queridas e especialmente cuidado com a nossa grande e generosa Mãe, a Terra. Sonhamos com o cuidado assumido com o ethos fundamental do humano e como compaixão imprescindível para com todos os seres da criação.

Romper com a visão individualista, competitiva e antropocêntrica é urgente e necessário. Perceber-se parte integrante e interdependente das outridades, sejam elas pessoas ou quaisquer outras formas de vida, é condição para a construção de uma Racionalidade Ambiental. Isso significa ter consciência de que somos parte da natureza e de que não devemos percebê-la como recurso, propriedade, produto, bem, consumo. A sociedade de consumo, em nome da vaidade, ganância e ambição, trata as 
relações socioambientais como mercadorias, com base na exploração e na degradação dos seres e da vida e na exclusão social. Sobre essa visão sistêmica, Boff (1999, p. 10) problematiza:

A primeira mudança começa com outra visão da realidade. A Terra está viva e nós somos sua porção consciente e inteligente. Não estamos fora e em cima dela, mas participando da rede de relações que envolve todos os seres, para o bem e para o mal. Se poluo o ar, acabo adoecendo e afetando todos os demais seres vivos. Se recupero a mata ciliar do rio que passa em meu terreno, preservo as águas, colaboro para com o aumento de seu volume e melhoro minha qualidade de vida, dos pássaros e dos insetos que polinizam as árvores frutíferas e as flores do jardim.

O que é uma visão aparentemente romântica desvela, na realidade, uma Racionalidade Ambiental de cuidado que deveria ser consciente e vivenciado por toda a humanidade. Esse processo individualista,assim como o descuido e o descaso do ser humano consigo e com o restante das formas de vida, banalizou processos de degradação ambiental, desencadeando uma crise civilizatória. Segundo Pereira (2016, p. 60), “[...] a lógica capitalista do consumo não nos cuida. Ela estimula concorrência desenfreada entre nós [...] na busca pelo ter mais, esvaziamos o sentido ontológico da existência humana”. Para o autor, esse processo sobrepõe o amor-próprio de propriedade e do orgulho ao amor de si. A lógica capitalista fragiliza o Cuidado Ambiental e reforça falsos discursos sustentáveis. A esse respeito, Boff (2013, p. 11) critica: “[...] Se falam de aquecimento global e de mudanças climáticas é, quase sempre, nesta ótica: quanto posso perder nesse fenômeno? Ou então, como posso ganhar comprando ou vendendo bônus de carbono? [...] A sustentabilidade de que falam não é adjetiva, nem substantiva. É pura retórica".

Na perspectiva do cuidado, Pereira (2016, p. 61) propõe a Ecologia Cosmocena como novas possibilidades de ser e de viver, ressaltando que:

A Ecologia Cosmocena denuncia os excessos da lógica consumista e nos conclama a desenvolver, enquanto humanos, múltiplas formas de sensibilização poética, estética, afetiva, ecológica e espiritual, de cuidarmos uns dos outros. A natureza nos cuida. Somente emite o alerta como grito de socorro. Da falta de cuidado decorrem as enchentes, as catástrofes ambientais, novos eventos biofísicos que alteram os painéis geográficos em todo o planeta. Fruto da ganância motivada pela lógica do capital nos descuidamos tanto, que acabamos ferindo uns aos outros. (grifo do autor).

Nesse sentido, torna-se primordial o princípio do Cuidado Ambiental como base para a formação de professores. Um docente que tenha a compreensão do cuidado de si e do outro oportuniza o reinventar-se diante da vida, diante das crises civilizatórias que nos afetam. A Racionalidade Ambiental, na perspectiva do cuidado, assume e intensifica o compromisso ético, o compromisso com a vida, o compromisso ontológico.

Os resultados sinalizaram que a Racionalidade Ambiental está na gênese da concepção epistemológica dos Institutos Federais e que a formação de professores pode potencializar a Educação Ambiental na instituição.

\section{Considerações Finais}

Consideramos importante problematizar os diferentes saberes para que outra racionalidade seja compreendida e reconhecida e buscar nos fundamentos da Educação Ambiental uma Racionalidade Ambiental - não como solução, mas para criar condições para outros saberes. É crucial que os saberes foquem, desde a formação de professores para a Educação Profissional, a qualidade de vida nos mais diversos ambientes. Nesse viés, importa questionar a sociedade consumista e patológica, originada desse paradigma dominante na modernidade, e as consequências desse modo de pensar e agir para as

formas de vida vigentes. É importante ressaltar que "saber se a Educação Ambiental está ou não institucionalizada nos ambientes educacionais permite que outros órgãos de controle educacional e a sociedade como um todo se beneficiem, tanto da 
contribuição prática quanto motivacional, uma vez que estes ambientes são propícios a fomentar novos comportamentos em favor do meio ambiente" (Capponi et al., 2021, p. 14).

Resultados da pesquisa indicam que os princípios da Racionalidade Ambiental estão presentes na gênese dos Institutos Federais. Portanto, torna-se necessário resgatar e fortalecer as bases epistemológicas que fundamentam os Institutos Federais para que não se fragilizem diante da crise atual, para que se possa manter o paradigma de Educação emancipatória dos IFs.

Depreende-se que uma das principais alternativas para a Racionalidade Ambiental na Educação Profissional seja a formação de professores voltada para a Educação Profissional de forma contextualizada em suas especificidades, com base nos princípios de Racionalidade Ambiental.

A partir deste estudo, temos como perspectivas futuras planejar encontros formativos para e com os cursos de licenciaturas e programas especiais de formação pedagógica do Instituto Federal de Educação, Ciência e Tecnologia do Rio Grande do Sul-IFRS. Nossa intenção é alargar os espaços de discussão no âmbito de outros Institutos Federais por meio do Grupo de Trabalho - GT 08 sobre formação de professores da Associação Nacional de Pós-Graduação e Pesquisa em Educação - ANPED. As ações propostas propiciarão ampliar o diálogo sobre os princípios ontológicos de Educação Ambiental como possibilidade de tornarem-se diretrizes epistemológicas para a formação de professores, contribuindo com a vivência da Racionalidade Ambiental nos Institutos Federais.

\section{Referências}

Albuquerque, F. M., \& Galiazzi, M. C. (2011). A formação do professor em rodas de formação. Revista Brasileira de Estudos Pedagógicos, 92(231), 386-398.

Boff, L. (1999). Saber cuidar: ética do humano, compaixão pela terra. Vozes.

Boff, L. (2013). O cuidado necessário: na vida, na saúde, na educação, na ecologia, na ética e na espiritualidade. Vozes.

Capponi, N. F. et al. (2021). Educação ambiental e agenda 2030: percepção dos gestores de uma rede de ensino básico e superior privado. Revista Research, Societyand Development, 10(3), e3210312895.

Claro, L. C. (2018). Horizontes compreensivos da educação ambiental do campo: contribuição às outridades do campo (Tese de doutorado). Universidade Federal do Rio Grande, RS, Brasil.

Cousin, C. S. (2010). Pertencer ao navegar, agir e narrar: a formação de educadores ambientais (Tese de doutorado). Universidade Federal do Rio Grande, Rio Grande, RS, Brasil.

Derrida, J. (2008). Adeus a Emmanuel Levinas. Perspectiva.

Freire, P. (2005). Pedagogia do oprimido. Paz e Terra.

Freire, P. (2016). Pedagogia da esperança: um reencontro com a pedagogia do oprimido (23a ed.). Paz e Terra.

Ghedin, E. \& Franco, M. A. S. (2008). Questões de método na construção da pesquisa em educação. Cortez.

Grün, M. (2008). A importância dos lugares na educação ambiental. Revista do PPGEA/FURG-RS, especial, 1-11.

Guareschi, P. (1998). Alteridade e relação: uma perspectiva crítica. In: Arruda, A. Representando a alteridade (pp. 149-161). Vozes.

Heidegger, M. (2015). Ser e tempo. Vozes.

Levinas, E. (1980). Totalidade e infinito. Lisboa, Portugal: Edições 70.

Lima, C. A. (2011). O diário em roda, roda em movimento: formar-se ao formar professores no Proeja (Tese de doutorado). Universidade Federal do Rio Grande, Rio Grande, RS, Brasil.

Marandola Júnior, E., Holzer, W. \& Oliveira, L. (orgs). (2014). Qual o espaço do lugar? Geografia, epistemologia, fenomenologia. Perspectiva.

Merleau-Ponty, M. (1999). Fenomenologia da percepção. Martins Fontes.

Pereira, A.S., Shitsuka, D. M., Parreira, F. J., \& Shitsuka, R. (2018). Metodologia da pesquisa científica. UFSM Recuperado de: https://rep ositorio.ufsm.br/bitstream/handle/1/15824/Lic_Computacao_Metodologia - Pesquisa - Cientifica.pdf?sequence=1 
Research, Society and Development, v. 10, n.3, e41110313366, 2021

(CC BY 4.0) | ISSN 2525-3409 | DOI: http://dx.doi.org/10.33448/rsd-v10i3.13366

Pereira, K. B., Dinardi, A. J. \& Pessano, E. C. (2020). A abordagem da educação ambiental em um projeto pedagógico de um curso de ciências da natureza.Research, Societyand Development, 9(8), e101985200.

Pereira, V. A. (2016). Ecologia Cosmocena: a redefinição do espaço humano no Cosmos. Garcia Edizioni.

Relph, E. (2014). Reflexões sobre a emergência, aspectos e essência de lugar. In: Marandola Júnior, E., Holzer, W., \& Oliveira, L. (orgs). Qual o espaço do lugar?Geografia, epistemologia, fenomenologia (pp. 17-32). Perspectiva.

Sá, L. M. (2005). Pertencimento. In: Ferraro Júnior, L. A. (org.). Encontros e caminhos: formação de educadoras(es) ambientais e coletivos educadores(pp. 245-255). MMA.

Saraçol, P. V., Dolci, L. \& Pereira, V.(2016). Hermenêutica e educação: um encontro com a pesquisa social. In: Pereira, V. A. Hermenêutica \& educação ambiental: no contexto do pensamento pós-metafísico. Garcia Edizioni.

Vasconcelos, M. L. M. C. \& Brito, R. H. P. (2011). Conceitos de educação em Paulo Freire: glossário. Vozes.

Warschauer, C. (2001). Rodas em rede: oportunidades formativas na escola e fora dela. Paz e Terra. 